\title{
EFEITO DO EXTRATO DE MELIA AZEDARACH L. SOBRE A PREDAÇÃO DE ALEVINOS DE CARPA COMUM (CYPRINUS CARPIO) POR LARVAS DE NEURAESCHNA (ODONATA: AESHNIDAE)
}

\author{
TOMAZELLI JR., 0.19; FRANCO, G. M. S. ${ }^{2}$; CASACA, J. M. ${ }^{1 \mathrm{~b}}$; MUNARINI, A. C. ${ }^{3}$ \& DAL MAGRO, J.. \\ 1 - Epagri - Centro de pesquisa para agricultura familiar, Caixa Postal 791, CEP 89801 - 970 , \\ Chapecó - SC, e-mails: (a) osmartj@epagri.sc.gov.br; (b) jmcasaca@epagri.sc.gov.br \\ 2 - Programa de Pós-Graduação em Ciências Ambientais, Universidade Comunitária da Região de \\ Chapecó, Caixa Postal 1141, CEP 89.809-000, Chapecó - SC, e-mail: gfranco@unochapeco.edu.br \\ 3 - Área de Ciências Exatas e Ambientais - Universidade Comunitária da Região de Chapecó Caixa \\ Postal 1141, CEP 89.809-000; Chapecó - SC, e-mail: acmunarini@unochapeco.edu.br \\ *Corresponding author: jacir@unochapeco.edu.br
}

\begin{abstract}
Tomazelli Jr., O.; Franco, G. M. S.; Casaca, J. M.; Munarini, A. C. \& Dal Magro, J. 2011. Effect of the Melia azedarach $\mathrm{L}$. on the predation of common carp fingerlings (Cyprinus carpio) by larvae of Neuraeschna (Odonata: Aeshnidae). 2011. Braz. J. Aquat. Sci. Technol. 15(1): 19-25. ISSN 1983-9057. The presence of larvae of predator insects in fish farming ponds is one of the factors that contribute to the reduction of the survival of fingerlings and consequently to the decrease of production profits. Dragonflies, which belong to the order Odonata, lay their eggs directly in the water, are among the insects that have a harmful effect on fish farming. The larvae are aggressive carnivores and predate post-larvae fish and fingerlings, and thus become economically relevant plagues. The objective of this work is to study the occurrence of Odonata larvae in fish ponds and evaluate the effect of Melia azedarach extract adsorved in silica to control Odonata larvae predation on common carp. A total of 126 larvae (Insecta: Odonata) of the suborder Anisoptera were registered in the monitored ponds. Of those, 80 belonged to the family Aeshnidae and 46 to the Libellulidae. The genera Neuraeschna was dominant in the three sampled ponds and was used in the biological tests. During the predation tests of common carp fingerlings (Cyprinus carpio) by the Neuraeschna larva, the average consumption was of 5,2 and 7,2 fingerlings in the treatments with and without Cinamono Ethanolic extract (EEC), respectively. The adoption of good practises in Aquaculture and the sustainability of fish farming require the adoption of natural products.
\end{abstract}

Keywords: Neuraeschna, dragonfly, cinnamon, fish farm, Melia azedarach.

\section{INTRODUÇÃO}

Com o desenvolvimento da piscicultura no Brasil, surgiram problemas relacionados com a predação de alevinos por adultos e larvas de insetos aquáticos. Neste último caso, temos uma das grandes ameaças, as larvas de Odonata. O hábito altamente predatório dessas larvas tem constituído um problema não só no Brasil, mas também em outros países (Santos et al., 1988).

Nos viveiros de piscicultura, durante a alevinagem, a predação por odonatas, vulgarmente conhecidas por libélulas ou lavadeiras é um dos fatores que contribuem para a redução da sobrevivência dos alevinos e consequentemente para a diminuição dos lucros da produção (Pritchard, 1965; Tave et al., 1990; Zaniboni Filho, 2000).

Testes realizados por Tave et. al. (1990) sobre predação de larvas de "catfish", Ictalurus punctatus, em viveiros com densidades de 50.000 a 100.000 larvas de peixes por hectare de área alagada com e sem tratamento com metil paration constatou-se que a sobrevivência das larvas de "catfish" nos viveiros tratados foi de 79 a $98 \%$ e nos viveiros não tratados as larvas de libélula consumiram todas as larvas de catfish dentro de 47 dias. Em outro teste dos mesmos autores comparando a preferência de Pantala (Odonata: Libellulidae) sobre alevinos de tilápia, Oreochromis mossambicus, de cores escuras e douradas, observou-se uma predação significativamente maior sobre as tilápias escuras do que as douradas (Tave et al., 1990).

Estudando o potencial de predação de alguns insetos aquáticos Pantala (Libellulidae), Coenagrion (Coenagrionidae) e Notonecta (Notonectidae) sobre larvas de carpa comum, Cyprinus carpio, a predação das ninfas do gênero Pantala sp aumentaram em relação ao comprimento do corpo. Ninfas pequenas, médias e grandes consumiram em média 0,91, 1,5 e 2,5 larvas de carpa comum, respectivamente. Os dados também indicam que quanto maiores forem os insetos maiores são suas presas, com exceção da larva da Pantala sp. Quando as ninfas chegaram ao tamanho de $19 \mathrm{~mm}$ o consumo foi reduzido, provavelmente devido à preparação do inseto à metamorfose. O consumo médio diário dos gêneros Pantala, Coenagrion, Tropistermus, Notonecta e Sigara foram 1,64, 0,43, 0,34, 1,50 e zero, respectivamente (Gonzáles \& Leal, 1995). 
Com objetivo de testar alternativas para o controle destas larvas, Fonseca et. al. (2004) estudaram as principais espécies de Odonata presentes em pisciculturas da região de Divinópolis e Itaúna, Estado de Minas Gerais, e avaliaram o efeito do Bacillus thuringiensis var. israelensis sobre o terceiro, quinto e sétimo instares da espécie Pantala flavescens. As espécies encontradas foram Acantharion sp., Aphylla theodorina, Brachymesia furcata, Micrathyria hesperis, Pantala flavescens e Perithemis moorna. Aespécie mais frequente nas coletas foi $P$. favescens, totalizando $37 \%$ do total dos indivíduos coletados. Não houve efeito significativo do produto microbiano sobre o controle da espécie estudada.

São raros os trabalhos na região Oeste de Santa Catarina quanto à diversidade e abundância de larvas de odonatos em viveiros de piscicultura, podendo citar Klaus (2004), que registrou 13 gêneros da Ordem Odonata em tanques de piscicultura no município de São Carlos-SC. Diferente, do verificado nesta pesquisa, a autora registrou maior abundância dos gêneros da família Libellulidae, (Orthemis com 38,18\%, Perithemis, 30,18\% e Erythrodiplax, 24\%). Para a região estão catalogados 35 táxons de Odonata (Gabiatti, 2003 e Ravanello 2004 e 2007) em diferentes habitats (rios, riachos e represas).

Os produtos naturais começam a ser utilizados na aquicultura em substituição aos produtos sintéticos no controle de pragas e doenças abrindo novas fronteiras de estudo em graves problemas enfrentados por esta atividade. São ricos em uma grande variedade de nutrientes e um repositório de novos aditivos para alimentação de animais aquáticos. Podem ser utilizados como atrativos, para aumentar a digestibilidade dos nutrientes, melhorarem a conversão alimentar, incrementar o ganho de peso e no controle de parasitoses (Xiang \& Zhou, 2000); como imunoestimulantes em peixes de cultivo (Ardó et. al., 2008); antibacterianos sobre patógenos de peixes como Aeromonas hydrophila, Photobacterium damselae subsp. piscicida, Streptococcus iniae e Vibrio alginolyticus (Abutbul et al., 2005) e como antivirais (Balasubramanian et al., 2007)

O cinamomo, Melia azedarach L. (Meliaceae) pertencente à família Meliaceae, é originário da Índia e foi introduzido no Brasil há séculos, sendo notável pela extraordinária facilidade de adaptação e pela vigorosa expansão vegetativa. É uma planta sensível à umidade excessiva, além disso, reproduz-se facilmente (Murilo, 2002). São de conhecimento e uso popular as suas propriedades inseticidas. Entre os usuários existem indicações do preparo e modo de utilização de extratos dos frutos contra pulgões, gafanhotos e cochonilhas. Outras formas de utilização são indicadas, como por exemplo, espalhar ramos e folhas verdes da planta pelo chão do galpão e arredores para o controle de pulgas ou pendurar na parede para o controle de moscas. Trabalhos científicos têm demonstrado os efeitos dos extratos de cinamomo no controle de insetos e pragas na agricultura (Brunherotto \& Vendaramim, 2001) e a insetos vetores e transmissores de doenças (Prophiro et. al., 2008; Guirado \& Bicudo, 2009). Na agropecuária é utilizado popularmente e também tem sido pesquisado pelas suas propriedades anti-helmínticas e carrapaticidas (Vivan, 2005; Falbo et. al., 2008).

Os terpenos abrangem uma grande variedade de substâncias de origem vegetal e sua importância ecológica como defensivos de plantas está bem estabelecida. Os limonóides ou tetranortriterpenóides são provavelmente, os maiores representantes da classe dos terpenos com atividade inseticida representando 0 nível máximo na sequência de produção de terpenóides (Viegas Junior, 2003).

O cinamomo é uma fonte de limonóides ou terpenos complexos, com ação fagoinibidora e outras propriedades para o controle de insetos. (Fukuiama et al., 2000; Carpinella et al., 2002).

Este trabalho tem como objetivos estudar a ocorrência de larvas de Odonata em viveiros de produção de alevinos de carpa comum no município de ChapecóSC e realizar testes de predação destas larvas em alevinos de carpa comum com e sem exposição ao extrato etanólico das sementes do cinamomo.

\section{MATERIAL E MÉTODOS}

\section{Coleta das larvas de Odonata}

No período de outubro a dezembro de 2007 em uma propriedade particular, produtora de alevinos, situada a $27^{\circ} 04^{\prime \prime} 12^{\prime \prime S}$ e 52²42'28"O localizada na região Oeste de Santa Catarina, no município de Chapecó foi realizado o estudo prévio para identificação dos táxons de Odonata ocorrentes bem como suas abundancias. De posse dos resultados foi selecionado o táxon com maior ocorrência, abundancia e potencial predatório.

O preparo dos viveiros foi realizado através de calagem de fundo utilizando $200 \mathrm{~g} \mathrm{~m}^{-2}$ de calcário dolomítico e adubação orgânica com $100 \mathrm{~g} \mathrm{~m}^{-2}$ de cama de aviário peneirada. Os três viveiros amostrados possuem área superficial de 500, 505 e $510 \mathrm{~m}^{2}$, respectivamente viveiros 1,2 e 3 . O enchimento foi realizado durante dois dias com água oriunda de outros viveiros previamente fertilizados para que houvesse uma rápida floração do plâncton.

As larvas foram coletadas através de um coletor de arrasto de fundo (APHA, 1998) com malha de 300 $\mu \mathrm{m}$. Os arrastos foram padronizados nos três viveiros em três minutos em cada lateral (taludes ao longo do eixo longitudinal dos viveiros) e uma no centro do vivei- 
ro, com periodicidade quinzenal durante o período de alevinagem.

Em campo as amostras foram pré triadas e as larvas foram colocadas em sacos plásticos com água do próprio viveiro e transportadas vivas até o laboratório. O restante do sedimento foi acondicionado em sacos plásticos e levado imediatamente ao laboratório onde foi lavado em um jogo de peneiras com malhas de 3,0, 2,0 e 1,0 mm, e as larvas encontradas acondicionadas em álcool $70 \%$. Posteriormente as larvas foram identificadas ao nível gênero com o auxílio da chave de identificação publicada por Costa et al., 2004.

\section{Obtenção do extrato etanólico do cinamomo e adsorção em sílica gel}

Os frutos do cinamomo (1,34 kg) foram secos a temperatura de $40^{\circ} \mathrm{C}$ e submetidos à maceração com etanol por 7 dias em um percolador e homogeneizados em intervalos de 24 horas. Foram preparadas duas extrações, com biomassas vegetais diferentes, de 555,72 e 784,28 g, em $2 \mathrm{~L}$ de etanol cada. Após a extração, os macerados foram filtrados, recolhidos e concentrados em evaporador rotatório sob pressão reduzida, obtendo-se 57,67 g do extrato etanólico de cinamomo (EEC).

Para a realização dos testes de predação foram adsorvidas 27,67 g do EEC em $200 \mathrm{~g}$ de sílica Gel 60 $\mathrm{F}_{254}$ (Merck) em um evaporador rotatório com pressão reduzida até a retirada total do diclorometano, solvente de rápida evaporação utilizado para uma completa homogeneização.

\section{Testes de predação}

Os testes de predação de alevinos de carpa comum por larvas de Odonata (Neuraeschna sp.) foram realizados no Laboratório de Ecologia e Química da Unochapecó em sala climatizada a $23^{\circ} \mathrm{C}$ e foto período de 12 horas, seguindo a metodologia descrita por Soares et. al. (2003) com modificações. Neste experimento foram utilizados aquários de polietileno com dimensões de $17 \mathrm{~cm}$ de comprimento $x 11,5 \mathrm{~cm}$ de largura $x$ $10 \mathrm{~cm}$ de altura com capacidade para 1,0 L instalados em uma bancada e abastecidos com água de um poço tubular profundo. Os aquários foram preparados com $0,5 \mathrm{~cm}$ de areia sobre o fundo, previamente esterilizada a $121^{\circ} \mathrm{C}$ durante uma hora.

A determinação da concentração do EEC foi realizada através da pesagem da sílica adsorvida com o extrato e em seguida aplicada sobre o substrato de areia e adicionado água.

Os alevinos de carpa comum e as larvas de Odonata foram coletados simultaneamente com um puçá e um coletor de fundo com malha de $300 \mu \mathrm{m}$, respectivamente, e levados imediatamente ao laboratório, em água do próprio viveiro com aeração quando então foram tomadas as medidas de comprimento e biomassa tanto dos alevinos quanto das larvas de Odonata e aclimatados por 24 horas nas condições descritas acima. Para o início dos testes, procurandose manter a mesma densidade dos alevinos existentes nos viveiros de alevinagem ( 150 alevinos. $\mathrm{m}^{-2}$ ), foram distribuídos aleatoriamente três alevinos e uma larva de Odonata por aquário previamente preparado. Foram testados três tratamentos com cinco repetições: a) com exposição das larvas ao EEC adsorvido em sílica; b) sem exposição ao extrato e c) tratamento controle somente com alevinos. A concentração do EEC foi de $0,375 \mathrm{mg} \cdot \mathrm{L}^{-1}$ calculada previamente durante testes de toxicidade por Tomazelli Junior (2009).

Após o período de aclimatização as larvas de Neuraeschna foram colocadas uma hora antes dos alevinos, momento caracterizado como início do experimento. Foram efetuadas contagens a cada três horas dos alevinos remanescentes (vivos) em cada unidade experimental, sendo repostos os alevinos consumidos de modo que permaneceram três alevinos de carpa após cada contagem. O tempo total do experimento foi de 27 horas. Os dados da temperatura da água, concentração de oxigênio dissolvido (OD), pH e condutividade foram obtidos durante as avaliações, com oxímetro , pHmetro e condutivímetro digitais.

Para análise estatística foram utilizados o total de alevinos consumidos por aquário com e sem exposição ao EEC durante o período experimental e submetidos à análise de variância a 5\% de probabilidade (Teste F).

\section{RESUTADOS E DISCUSSÃO}

\section{Coleta das larvas de Odonata}

Nos três viveiros monitorados nesta pesquisa foi registrado um total de 126 larvas de Odanata da subordem Anisoptera, sendo 80 larvas pertencentes à família Aeshnidae e 46 à Libellulidae. Embora com maior número de larvas amostradas, a família Aeshnidae foi representada por somente três gêneros, Neuraeshna com 72, Rhionaeshna com 6 e Limnetron com duas larvas. Neuraeshna e Rhionaeshna foram os únicos gêneros que ocorreram nos três viveiros. Da família Libellulidae ocorreram sete gêneros (Tabela 1).

Do total das larvas amostradas, as pertencentes ao gênero Neuraeschna representaram 57,1\%. Erythrodiplax, Orthemis e Micrathyrya foram as mais abundantes da família Libellulidae com 14,29; 8,73 e $6,35 \%$, respectivamente. Os demais gêneros foram mais raros, dentre eles: Anatya (2,38\%), Dythemis (1,59\%), Nephepeltia (1,59\%) e Tramea (1,59\%). Todas as larvas, exceto Dythemis (descrita por habitar ambientes lóticos), são descritas por habitarem ambientes lênticos 
Tabela 1- Relação dos gêneros de Odonata presentes nos viveiros monitorados.

\begin{tabular}{lcccc}
\hline \hline & Viveiro 1 & Viveiro 2 & Viveiro 3 & Total \\
\hline Família Libellulidae & & & & \\
Erythrodiplax & 18 & & & 18 \\
Orthemis & 8 & & 3 & 11 \\
Micrathyria & 6 & & 2 & 8 \\
Anatya & 3 & & & 3 \\
Dythemis & 2 & & & 2 \\
Nephepeltia & 2 & & & 2 \\
Tramea & 2 & & & 2 \\
Família Aeshnidae & & & & \\
Neuraeshna & 22 & 31 & 19 & 72 \\
Rhionaeshna & 1 & 1 & 4 & 6 \\
Limnetron & 2 & & & 2 \\
Total & 66 & 32 & 28 & 126 \\
\hline \hline
\end{tabular}

incluindo-se tanques de piscicultura (Costa et. al., 2004).

As larvas de Neuraeschna ocorreram 15 dias após o alagamento dos viveiros com comprimento total de até $3,0 \mathrm{~cm}$ e, no final das coletas, apresentavam-se com as tecas alares bem desenvolvidas e em fase de emergência. Segundo Costa et. al. (2004), a Neuraeschna é uma larva de porte grande $(49-51 \mathrm{~mm})$, apresentando o dorso do abdome liso e vértex sem tubérculo. Todos os taludes de ocorrência desta larva apresentaram-se com declividade acentuadamente menor que os demais e com margens colonizadas por macrófitas aquáticas, evidenciando a associação dessas larvas a essa vegetação. As odonatas desta família enquadram-se nas que tem ovopositor desenvolvido, injetando os ovos nas plantas aquáticas ou mesmo detritos orgânicos flutuantes (postura endofítica), sendo esta uma característica importante para combater a predação (Santos et al., 1988). Ainda, possuem as formas de vôo mais velozes e de maior porte entre os Anisoptera. As asas posteriores, principalmente dos machos, apresentam o triângulo anal formado por 2-4 células. Os adultos, são facilmente reconhecidos pela semelhança entre os triângulos das asas anteriores e posteriores ocorrendo em ambientes lênticos, habitando poças d'água e brejos (Costa, et. al., 2000; Costa et. al., 2004).

Um aspecto importante do comportamento das larvas de Odonata é o canibalismo. As larvas da família Aeshnidae são muito predadoras e atingem o maior porte entre as odonatas brasileiras (Santos et. al., 1988). Provavelmente este comportamento predatório e as condições para uma postura endofítica sejam a respostas para a dominância das larvas da família Aeshnidae.
Tabela 2 - Média e desvio padrão das variáveis físico químicas da água nos três viveiros amostrados.

\begin{tabular}{cccc}
\hline \hline Viveiros & $\begin{array}{c}\text { Temperatura } \\
\text { da água }\left({ }^{\circ} \mathrm{C}\right)\end{array}$ & $\begin{array}{c}\text { Oxigênio } \\
\text { Dissolvido } \\
\left(\mathrm{mgL}^{-1}\right)\end{array}$ & $\mathrm{pH}$ \\
\hline 1 & $24,12 \pm 2,00$ & $7,97 \pm 2,49$ & $6,88 \pm 0,48$ \\
2 & $24,25 \pm 1,48$ & $9,49 \pm 2,41$ & $6,80 \pm 0,19$ \\
3 & $25,20 \pm 0,89$ & $6,59 \pm 3,00$ & $6,71 \pm 0,23$ \\
\hline \hline
\end{tabular}

Umas das odonatas mais citadas e estudadas como predadoras de larvas e alevinos é a Pantala flavescens (Soares et al., 2001; Fonseca et. al., 2004; Lacerda, 2007). Cabe ressaltar que durante o monitoramento realizado esta larva não foi encontrada, porém, durante coletas esporádicas a mesma foi capturada no final do mês de fevereiro e início de março de 2007 e 2008 em viveiros cujas despescas já haviam sido realizadas.

Na Tabela 2 encontram-se os valores das variáveis físico químicas da água aferidas nos três viveiros amostrados. Segundo Boyd (1982), encontram-se dentro da faixa considerada ideal para piscicultura.

\section{Testes de predação}

Como a larva Neuraeschna apresentou maior ocorrência durante a avaliação dos viveiros e pelo seu potencial predatório, ela foi utilizada nos testes de predação. No comprimento total as odonatas eram 1,6 vezes maiores que os alevinos de carpa comum, porém, 10,0 vezes mais pesadas que os mesmos, evidenciando a desvantagem dos alevinos em relação ao seu predador.

Foi observado comportamento de predadora voraz com perseguição e ataque às suas presas, sendo que na primeira leitura nos dois tratamentos foi observado o maior número de alevinos predados, possivelmente devido à restrição alimentar durante aclimatação de 24 horas a que foram expostas as larvas de Odonata. Foram nove alevinos predados no tratamento sem o EEC e 10 alevinos no tratamento com o EEC.

O total de alevinos predados foi $15,4 \%$ superior no tratamento com o EEC até a terceira leitura, a partir daí o número de alevinos predados foi menor do que no tratamento sem exposição ao EEC até o final do experimento. No tratamento com EEC foi observado redução na predação dos alevinos e lentidão nos movimentos das larvas de Neuraeschna em relação às larvas sem exposição ao EEC, possivelmente devido ao efeito tóxico provocado pelo contato com o extrato de cinamomo. Houve diferença significativa $(p<0,05)$ no consumo dos alevinos entre os tratamentos com e sem exposição das larvas de Neuraeschna ao EEC. 
Tabela 3 - Peso dos alevinos de carpa comum (Cyprinus carpio), das larvas de Neuraeschna, média e desvio padrão das variáveis físico químicas da água durante os testes de predação.

\begin{tabular}{lcccccc}
\hline \hline Tratamentos & $\begin{array}{c}\text { Peso dos } \\
\text { alevinos } \\
(\mathrm{g})\end{array}$ & $\begin{array}{c}\text { Peso das } \\
\text { larvas }(\mathrm{g})\end{array}$ & $\begin{array}{c}\text { Temperatura } \\
\text { da água }\left({ }^{\circ} \mathrm{C}\right)\end{array}$ & $\begin{array}{c}\text { Oxigênio } \\
\text { Dissolvido } \\
\left(\mathrm{mgL}^{-1}\right)\end{array}$ & $\mathrm{pH}$ & $\begin{array}{c}\text { Condutividade } \\
\left(\mu \mathrm{S} . \mathrm{cm}^{-1}\right)\end{array}$ \\
\hline Com EEC & $0,13 \pm 0,01$ & $1,29 \pm 0,193$ & $22,51 \pm 0,07$ & $5,52 \pm 0,58$ & $7,02 \pm 0,06$ & $94,4 \pm 3,8$ \\
Sem EEC & $0,14 \pm 0,01$ & $1,35 \pm 0,148$ & $22,50 \pm 0,47$ & $5,62 \pm 0,43$ & $7,01 \pm 0,05$ & $98,6 \pm 3,9$ \\
Controle & $0,13 \pm 0,01$ & $1,27 \pm 0,15$ & $22,51 \pm 0,48$ & $5,63 \pm 0,45$ & $7,01 \pm 0,05$ & $95,2 \pm 4,1$ \\
\hline \hline
\end{tabular}

A diferença na predação dos alevinos acentuouse a partir do momento em que começou a mortalidade das larvas de Odonata expostas ao EEC, com uma larva morta às 24 horas. Às 27 horas do experimento não houve predação pelas larvas expostas ao EEC apresentando visualmente comportamento sem reflexos á predação quando comparadas com as larvas sem exposição ao EEC. No tratamento sem exposição ao EEC não houve mortalidade das larvas de Odonata durante o período experimental e a predação dos alevinos continuou até o final do experimento.

O consumo médio de alevinos durante as 27 horas do experimento foi de 5,2 e 7,2 para as larvas de Neuraeschna com e sem exposição ao EEC respectivamente. Na figura 1 encontra-se o consumo acumulado dos alevinos de carpa comum de todos os tratamentos, indicando a maior predação nos aquários sem exposição ao EEC e o fim da predação a partir das 24 horas nos aquários com exposição ao EEC.
Os valores encontrados por Tave et. al., (1990) em testes de predação da Odonata, Pantala $s p$.(Libellulidae) sobre alevinos de tilápia foram de 6,6 larvas de tilápia por dia. Gonzáles \& Leal (1995) avaliou o potencial de predação de vários insetos aquáticos sobre alevinos de carpa comum. Pantala sp. foi o predador mas efetivo com 1,64 larvas de carpa comum diariamente, seguida de Notonecta $(1,5)$, Coenagrion $(0,43)$, e Tropistemus larvae $(0,35$ larvas de carpa/dia).

No tratamento controle, não houve mortalidade dos alevinos de carpa e os mesmos apresentavam comportamento e reflexos normais. Não houve diferença significativa $(p>0,05)$ nas variáveis físico químicas da água entre os tratamentos (Tabela 3). Os valores aferidos se encontram dentro da faixa considerada ideal para piscicultura (Boyd, 1982).

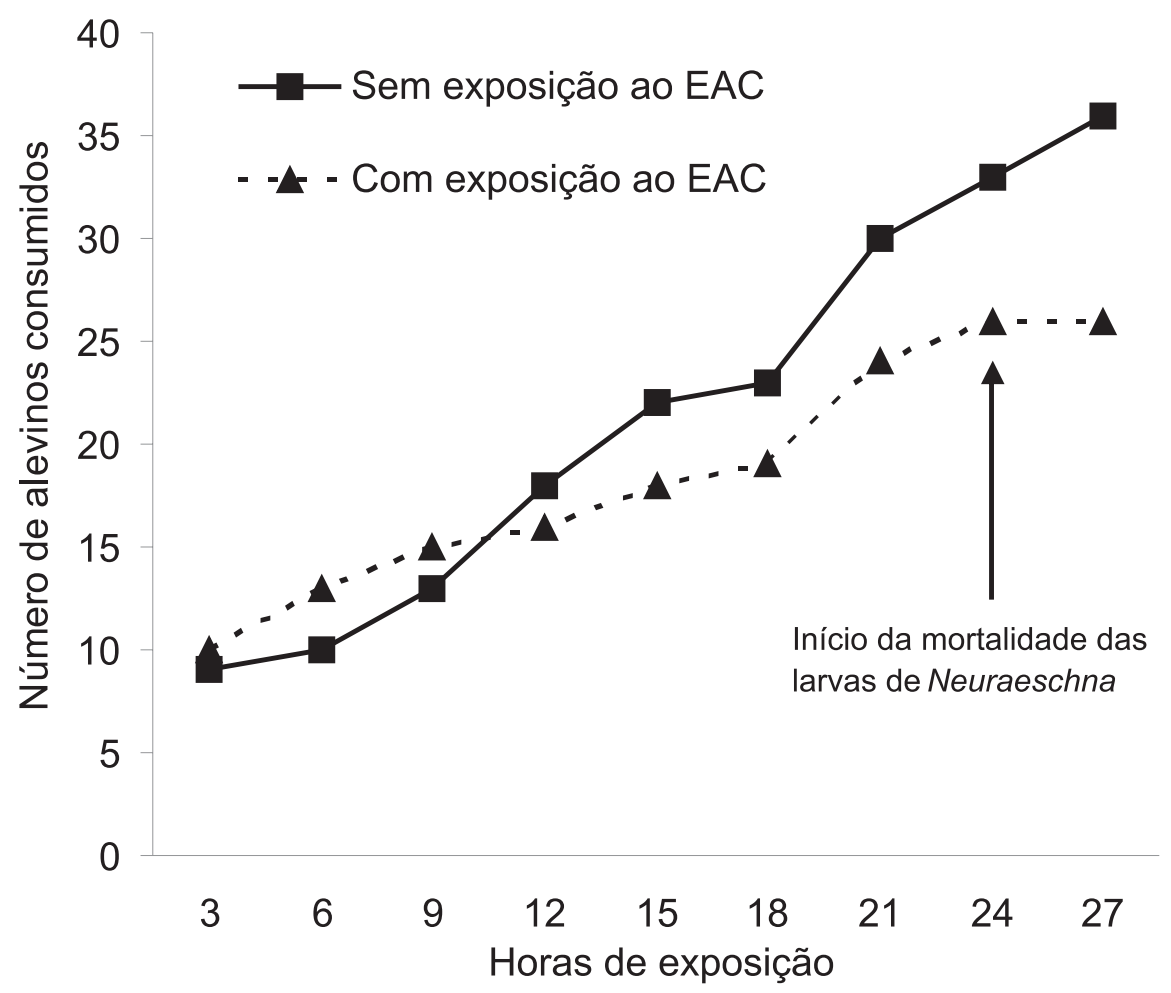

Figura 1 - Consumo acumulado de alevinos de carpa comum pelas larvas de odonata durante os testes de predação. 


\section{CONCLUSÕES}

A maior ocorrência da larva de Neuraeschna nos viveiros estudados a coloca como a principal predadora dos alevinos de carpa entre as odonatas.

O EEC disponibilizado no fundo dos aquários apresentou efeito sobre as larvas de Neuraeschna, com redução alimentar e mortalidade das mesmas. Entretanto mais estudos são necessários principalmente a fim de testar o efeito do extrato de cinamomo no desenvolvimento ontogenetico da Neuraeschna, para que se possa otimizar o manejo destes predadores nos tanques de piscicultura.

Para uma aqüicultura sustentável baseada em práticas que respeitem o meio ambiente a busca por produtos naturais para o controle de pragas e doenças é um caminho que pode ser percorrido.

\section{REFERÊNCIAS}

Abutbul, S., Golan-Goldhirsh, A., Barazani, O.; Ofir, R. \& Zilberg, D. 2005. Israeli Journal of Aquaculture Bamidgeh. 57(2): 71-80.

APHA, American Public Health Association. 1998. Standard Methods for the examination of Water and Wastewater. 20. Edição. Washington, 560p.

Ardó, L.; Yin, G.; Xu, P.; Váradi, L.; Szigeti, G.; Jeney, Z. \& Jeney, G. 2008. Chinese herbs (Astragalus membranaceus and Lonicera japonica) and boron enhance the non-specific immune response of Nile tilapia (Oreochromis niloticus) and resistance against Aeromonas hydrophila. Aquaculture. 275(1): 26-33.

Balasubramanian, G.; Sarathi, M.; Kumar, S. R. \& Hameed, A. S. S. 2007. Screening the antiviral activity of medicial plants against White spot syndrome virus in shrimp. Aquaculture. 263(1-4): 1519.

Boyd, C. E. 1982. Water quality management for pond fish culture. Elsevier, Amsterdan, 318p.

Brunherotto, R. \& Vendramim, J. D. 2001. Bioatividade de estratos aquosos de Melia azedarach L. sobre o desenvolvimento de Tuta absoluta (Meyrick) (Lepidoptera: Gelechiidae) em tomateiro. 2001. Neotropical entomology. 30(3): 455-459.

Carpinella, C.; Ferrayoli, C.; Valladares, G.; Defago, M. \& Palacios, S. 2002. Potent limonoid insect antiffedant from Melia azedarach. Biosci. Biotechnol. Biochem. 66(8): 1731-1736.

Costa, J. M. C.; Machado, A. B. M.; Lencioni, F. A. A. \& Santos, T. C. 2000. Diversidade e distribuição dos ODONATA (INSECTA) no estado de São Paulo, Brasil: Parte 1 - Lista das espécies e registros bibliográficos. Publ. Avul. Mus. Nac. Rio de Janeiro. 80: 1-27.

Costa, J. M., Souza, L. O. \& OLDRINI, B. B. 2004. Chave para famílias e gêneros das larvas de Odonata citadas para o Brasil: comentários e registros bibliográficos. Publ. Avul. Mus. Nac., Rio de Janeiro. 99: 1-44.

Falbo, M. K.; Sandini, I. E.; Ishiy, H. M.; Fávero, J. L.; Santos, C. E.; Bastos, S.; Rogigheri, D. \& Guzzo, D. 2008. Atividade anti-helmíntica do fruto de Melia azedarach em cordeiros naturalmente infectados com nematódeos gastrintestinais. Ciências Agrárias. $29(4): 881-886$.

Fonseca, R. A.; Sanches, N. M.; Fonseca, M. C.; Quintilhiano, D. M. \& SILVA, E. S. 2004. Levantamento de espécies de Odonata associadas à tanques de piscicultura e efeito de Bacillus thuringiensis var. israelensis sobre ninfas de Pantala falvescens (Fabricius, 1798) (Odonata: Libellulidae). Acta Scientiarium. 26(1): 25-29.

Fukuiama, Y.; Ogawa, M.; Hironobu, T. \& Minami, H. 2000. The new meliacarpinins from the roots of Melia azedarach. Chem. Farm. Bull. 48(2): 301-303.

Gabiatti, R. L. 2003. Fauna de odonata do rio caçador, Seara-SC.Trabalho de Conclusão do Curso de Ciências Biológicas. Universidade Comunitária Regional de Chapecó - UNOCHAPECÓ. 16p.

Gonzáles, A. V. \& Leal, J. M. 1995. Predation Potential of some aquatic insects (Pantala, coenagrion, Tropisternus, Notonecta and Sigara) on Common Carp Fry. 1995. Journal of Applied Aquaculture 5(1): 77-82.

Guirado, M. M. \& Bicudo, H. E. M. C. 2009. Alguns aspectos do controle populacional e da resistência a inseticidas em Aedes aegypti (Dipetera, Culicidae). Bepa. 6(64): 5-14.

Klaus, G. R. 2004. Identificação de náiades de odonata em tanques de piscicultura no município de São Carlos - SC. Trabalho de Conclusão do Curso de Ciências Biológicas. Universidade Comunitária Regional de Chapecó -UNOCHAPECÓ. 21p.

Lacerda, C. H. F. 2007. Influência da turbidez, macrófitas aquáticas e tamanho das ninfas na predação de larvas de Piaractus mesopotamicus e Oreochromis niloticus por odonata Pantala favescens. Tese de Mestrado. Universidade Estadual de Maringá. 52p.

Murilo, F. 2002. Avaliação de plantas com potencial inseticida no controle da vaquinha-do-feijoeiro (Cerotoma tingomarianus Bechyné). Boletim de Pesquisa, 37. Embrapa Acre. Rio Branco, Acre, 42p.

Pritchard, G. 1965. Prey capture by dragonfly larvae (ODONATA: ANISOPTERA). Canadian Journal of Zoology. 43: 271-289.

Prophiro, J. S.; Rossi, J. C. N.; Pedroso, M. F; Kanis, L. A. \& Silva, O. S. 2008. Leaf extracts of Melia 
azedarach Linnaeus (Sapindales: Meliaceae) act as larvicide against Aedes aegypti (Linnaeus, 1762) (Diptera: Culicidae). 2008. Rev. Soc. Bras. Med. Trop. 41(6): 560-564.

Ravanello, C T. 2007 Diversidade e abundância de larvas de Odonata (insecta) em nove rios da bacia hidrográfica do Alto Rio Uruguai - Santa Catarina. Tese de Mestrado. Universidade Comunitária Regional de Chapecó - UNOCHAPECÓ. 80 p.

Ravanello, C. T. 2004. Diversidade de Odonata (INSECTA) no rio Lajeado São José, Chapecó-SC. Trabalho de Conclusão do Curso de Ciências Biológicas. Universidade Comunitária Regional de Chapecó - UNOCHAPECÓ. 21p.

Santos, N. D.; Costa, J. M. \& Pujol-Luz, J. R. 1988. Nota sobre ocorrência de odonatos em tanques de piscicultura e o problema de predação de alevinos pelas larvas. Acta Limnol. Brasil. 11: 771-780.

Soares, C. M.; Hayaxhi C.; Esper, A. C. \& Faria, A. C. E. A. 2001. Influência da disponibidade de presas, do contraste visual e do tamanho das larvas de Pantala sp. (Odonata, Insecta) sobre a predação de Simocephalus serrulatus (Cladocera). 2001. Acta Scientiarum. 23(2): 357-362.

Soares, C. M.; Hayaxhi C.; Reidel, A. 2003. Predação de pós-larvas de curimba (Prochilodus lineatus, Valenciennes, 1836) por larvas de Odonata (Pantala, Fabricius, 1798) em diferentes tamanhos.; Acta Scientiarum. 25(1): 95-100.
Tave, D; Rezk, M. \& SMITHERMAN.. O. 1990 Aquaculture and fisheries management. 212: 157161.

Tomazelli Júnior, O. 2009. Uso de extratos vegetais no controle de larvas de insetos aquáticos (ODONATA: LIBELLULIDAE) predadores de alevinos em viveiros de piscicultura. Tese de Mestrado. Universidade Comunitária da Região de Chapecó UNOCHAPECÓ. 77p.

Viegas Junior, C. 2003. Terpenos com atividade inseticida:Uma alternativa pra o controle químico de insetos. 2003. Quim. Nova. 26(3): 390-400.

Vivan, M. P. 2005. Uso do cinamomo (Melia azedarach) como alternativa aos agroquímicos no controle do carrapato bovino (Boophilus microplus). 2005. Tese de Mestrado. Universidade Federal de Santa Catariana - UFSC. 72p.

Xiang X. \& Zhou X. H. 2000. Application effect of Chinese herb medicine to aquatic animal feeds. Cereal Feed Ind. 3: 27-29.

Zaniboni Filho, E. 2000 Larvicultura de peixes de água doce. Informe agropecuário. Belo Horizonte. 21(203): 69-77. 